I shell.now reed notes of two cases in which the carber Itato of ammonis was eminently successful.

CABE 1. 8. E., aged 17 jears, had lately sufiered from an attack of continued fever. Diarrhos continued during his convalescence, and for some time after he had so far recovered as to be able to walk about. On the 21st of May last, I prescribed grain doses of carbazotate of ammonia and gallic acid, with one sixth of a grain of opium, three times a day. On the 26th, i. e., five days afterwands, I saw him again; and he had improved. On the 2nd of June, the him again ; and he had, and continued daily. On the 7 th, I reported him cured.

This young man had not been free from diarrhoea for three months previous to his taking the above medicines; and, during that period, gallic acid, acetate of lead, and opium, were administered without effect. He is now quite well.

Case Ir. The next case was one of diarrhcea, of eighteen months' standing. The patient was suffering from menthe 4th of June, he began the same remedies, in similar quantities as June, he began the preceding case. I lost sight of this patient for a time. I saw him, however, five days ago; and he said that he did not return, as the "bowel complaint was quite gono". Acetate of lead and opium had been administered in this case also without any good result. The sycosis is no better.

There is a circumstance in connexion with this subject of much physiological interest; and I feel that I shall not hare performed my part if $I$ do not bring it under your notice.

I have prescribed carbazotic acid and the carbazotates of potassa, ammonia, iron, and zinc, in eight cases; and, in four of these, the skin and conjunctiva became yellow during the administration of the remedies. They were completely jaundiced; and I believe that the yellowness was owing to the colouring matter of the remedies having tinged the serum of the blood. The coloration may have been owing to some change produced in the biliary system by the remedies; but I am inclined to the former opinion. The tinge of the skin and conjunctiva so perfectly resembles jaundice, that the keenest observer would be deceived; and I believe that, if the fact were generally known, there would be jaundiced impostors and malingerers without end.

In conclusion, I beg to remind you that Professor Crace Calvert will be most happy to supply any of you with small quantities of the articles, provided you will let him have the result of your experience. Your reports may be sent direct to him, or through me; and I shall be very glad to be the means of supplying any of you with the articles, and forwarding any reports you may favour me with. I beg to express a hope that some of you will try the remedies; for when we consider that, as has been before stated, Dr. Bell has cured several cases of ague with the carbazotic acid, and that the carbazotates appear to possess tonic qualities equal to quinine (one ounce of which is double the price of one pound of the other articles), their introduction into hospital and union practice is of paramount importance.

Hawarden, July 1855.

I

\section{CASE OF POISONING BY CHLORIDE OF ZINC.}

By GEORGE WILLIS, M.D.

Mr. P., on the 29th April, at 1 P.M., swallowed by mistake about an ounce of Crews' disinfecting liquid : this is, I believe, a saturated solution of chloride of zinc. On my arrival, five minutes after the accident, I found Mr. P. vomiting, having previously swallowed a large quantity of water. The matter then rejected had to me no very styptic taite. I thought it desirable to promote the vomiting, and gave large draughts of warm water and of infusion of blect to The patient was then complaining of great pain and heat in the stomach and bowels.

In the course of half an hour, he pessed a large loose and watery motion; after that he wont to bed, and had and watery motion; after that pain, and gum-water for drink, with pounded ice in it.

In the evening, desire to go to stool was accompanied for two hours by the discharge of nearly three pints of mucus mixed apparently with shreds of the intestinal mucous membrane. There was not abdominal tendernees, a hard jerking pulse, constant nausea, and occasional romiting.

At 10 P.M., I applied six leeches to the abdomen, and promoted the bleeding by hot poultices. Two hours afterwards, the patient fell into a tranquil sleep, which lasted throughout the night.

During the ensuing fire days, the treatment consisted in giving very little food, and that liquid and cold; the most distressing symptom was flatulency; this was greatly relieved by mixing lime-water with his milk diet. I should lieved by mixing lime-water with and fauces had escaped injury; Mr. P. having, what is vulgarly called, "bolted" the dose, thinking it to be fluid magnesia. By this time the abdominal tenderness had passed away; the pulse had lost much of its jerking feel; the bowels had acted the lost much of its jerking after the accident; the stool was mixed with mucus, and deficient in bile. The fact of his being the subject of chronic hepatic disease made this symptom appear of little importance.

May 5th. The case to day suddenly assumed a less favourable aspect. He complained of a throbbing in every part; the tongue was dry, red, and glazed; the pulse part; the tongue to-day three clay-coloured motions, the quick, he passed a tape-like appearance. He was ordered to take a pill of hydrargyrum cum creta, with extract of to take a pill of hydrargyrum cuming draught, containing liquor ammoniæ acetatis and spirits of nitric æther, every four hours.

May 7th. The tongue was moist, but very red; the secretions from the bowels more natural; spirits good. The patient, on his part, declared himself well, and asked to discontinue his medicine, and have animal food for dinner.

May 8th. This morning he felt sick, and rejected a quantity of dark coloured thick fluid from the stomach; he also passed a little tar-like matter from the bowels. I ordered a turpentine mixture, and pills containing acetate of lead and creasote, every three hours.

May 9th. He felt quite comfortable, and in excellent spirits; all his symptoms appeared alleviated.

May 10th. I was called up early to find my patient much worse. He had had no sleep all night, and was suffering from nausea; his belly was distended, his counfering from nausea, ha his pulse was small and quick. While at the night-chair passing a large quantity of melena, he romited three pints of black fluid blood, and was carried fainting into bed, where he died in three hours from that time. At the post mortem examination, made forty-eight hours afterwards, I found the abdomen tense and distended with gas, but no trace of peritoneal inflammation. There was cirrhosis of the liver from the previous habits of life. The pyloric end of the stomach was 80 soft as to be torn through in its removal, and the stomach and small intestines were full of blood. Large patches of ulceration were found in the stomach and small intestines.

Cases of poisoning with chloride of zinc are rare. One instance, in which a child was nearly killed by drinking some of Crews' liquid, is recorded in the Associarion JodRNAL for November 24th, 1854,

Monmonth, July 29th, 1855. 